\title{
Research on the Impact of China Factors on Pricing of International Bulk Commodities
}

\author{
Ying Chen \\ Wuchang University of Technology, Wuhan Hubei, 430223,China
}

Key words: China factors, International bulk commodities, Pricing power.

\begin{abstract}
In recent years, "China factors" have made a significant contribution to the global economic development; meanwhile, we have the difficulty in pricing power for imported and exported bulk commodities; the price fluctuation ranges of many bulk commodities greatly exceed the reasonable ranges that reflect the supply-demand relationship, bringing a huge economic loss to our country. On that account, how to enhance and strive for international discourse power and pricing power of bulk commodities is of great significance to smoothly promoting our economic transition and maintaining the healthy development of our economy. This paper analyzes the current situation of China in pricing power of international bulk commodities, discusses the existing problems of China factors in the pricing process of international bulk commodities, and puts forward countermeasures for further enhancing the impact of China factors on pricing of international bulk commodities.
\end{abstract}

\section{Introduction}

Since the reform and opening up, our economy has developed rapidly and is increasingly dependent on international bulk commodities; by 2011, China had accounted for $10 \%$ in global GDP and consumed $12 \%$ of the global oil output, $37 \%$ of aluminum output, $38 \%$ of copper output and $49 \%$ of coal output. China has become one of the most important bulk commodity consumers. However, we fail to grasp enough pricing power of bulk commodities and can only accept the prices passively, which not only increases the operational cost, but also weakens the competitive advantage in price and shrinks the profit margin. Nowadays, with the implementation of "One Belt and One Road" strategy and the promotion of RMB internationalization, a new opportunity comes for our country to strive for pricing power of international bulk commodities.

\section{China's current situation in pricing power of international bulk commodities}

The international pricing power of bulk commodities refers to the power of confirming the specific prices of bulk commodity transaction. In recent years, we have often encountered the difficulty in pricing power in the international trade process, bringing a huge loss to our economic development. For example, as the largest country producing and exporting rare earth in the world, we hardly have the discourse right in international pricing of rare earth, resulting in long-term low export price of rare earth. Although the export volume of our rare earth grows continuously, the average price decreases ceaselessly. According to the current price, the profit of rare earth enterprises is just around 5\%, showing a typical low-profit industry. As a rare earth exporting country with a huge output, our obvious price deviation of rare earth is so confusing. Therefore, in order to obtain the international pricing power of bulk commodities, China factors need to be turned into China advantages, so as to deal with the risks caused by price fluctuation to Chinese economy and enhance the initiative right of our enterprises in international market. 


\section{Problems of China factors in the pricing process of international bulk commodities}

\section{Firstly, Low concentration ratio in industries}

Our foreign trade develops very fast; since the reform and opening up, our value of international trade generally grows by over $20 \%$ on a annual basis; however, there is little change to the market competition condition in some domestic industries, and the concentration ratio in each industry is not high; there are many main trading bodies, but the industry scale is not large; the vicious competition occurs among enterprises and there is no consistent sound to the outer world, which will certainly result in the lack of sufficient influence. For example, although we have already had the advantage of resource monopoly in rare earth, this industry has not cultivated and formed large influential enterprises in domestic and foreign markets, resulting in numerous enterprises in this industry with a very low concentration ratio; the excess production capacity will certainly cause the vicious competition in price. With the merging of domestic rare earth related enterprises in recent years, enterprises can stand out from the crowd, obtain the discourse right and lead this industry only through the crucial market competition, rather than just relying on national strategies.

Secondly, No close sales and purchasing alliances among trading enterprises

There are a large number of international trading enterprises in our country and government's administrative departments and industrial management are insufficient, thus many enterprises go their own ways without order in the links of both export and import; besides, the lack of corresponding industry supervision and restraint results in disorder of enterprises in international trade, excessive speculation atmosphere and increasingly vicious competition; thus, it is difficult to form a very close sales and purchasing alliance, resulting in the situation that relevant enterprises lack the ability of fighting for the market pricing power within the global range and have to accept the unfair pricing passively; this consequently leads to the situation that our iron and steel enterprises often encounter the price increase when importing iron ores and price decrease when exporting rare earth. Therefore, although there are a lot of enterprises participating in international trade, we have to passively accept the pricing of international bulk commodities if we fail to establish a close sales and purchase alliance.

Thirdly, Weak technical innovation capabilities of enterprises

Though we have some advantageous resources, it is difficult for us to make full use of them and we could not get the pricing power of bulk commodities by relying on our own advantageous resources. One of the most fundamental reasons is that the overall technical innovation capability of our enterprises is weak and it is difficult to practically turn our resource advantage into the industry advantage with higher added value. As far as rare earth is concerned, although our country is the largest country producing and exporting rare earth, our technical research in the rare earth field lags behind United State, Japan and some other countries greatly. The technical deficiency results in low utilization efficiency of rare earth. Take Japan as an example: $90 \%$ of rare earth in Japan is consumed for the high-tech field, creating favorable economic benefits; however, the amount of rare earth consumed for the high-tech field does not account for half of the total amount. Rare earth materials with high purity are often grasped by western developed countries, and the rare earth products exported by our country are mainly the rare earth processed products with low added value, and this is why it is difficult to strive for the corresponding discourse power in the international market.

\section{Countermeasures for further enhancing the influence of China factors on pricing of international bulk commodities}

\section{Implement the "one belt and one road" strategy to enhance the discourse right for pricing of international bulk commodities}

The main train of thought of China's construction of "one belt and one road" is to interconnect with the external world so as to facilitate the realization of butt joint among the development strategies of all countries along the line, achieve the joint economic development of countries concerned, thus 
form a benefit community, enhance the level of opening to the outside world, form a new situation of comprehensive opening and fully integrate into the global economic system. It is an unprecedented good chance for the development of China's bulk commodity industry. A large number of our country's bulk commodities completely rely on import so their strike prices are all determined based on the prices in the international markets. After the implementation of one belt and one road, it has offered a very good development opportunity for our country to establish and participate in the platform for transactions of international bulk commodities and resource allocation. At present, the pricing of global bulk commodities is determined based on the prices of London Metal Exchange. If our country builds and develops spot and futures exchanges for bulk commodities with the one-belt-one-road strategy, sets delivery libraries as well as formulate and issue just and fair laws and regulations, we can enhance our country's competitiveness in bulk commodity transaction and lay a foundation for our country's future winning of pricing right for bulk commodities.

\section{Enhancing the pricing right for bulk commodities through the course of RMB internationalization}

China's course of RMB internationalization is to make the international society to rely on RMB in essence. When the scale of financial markets pricing with RMB expands continuously and the RMB settlement in traded commodities reach a certain proportion, Chinese government will hold the power of initiative. In order to change the situation of favorable balance of trade, Chinese government needs to import many materials needed so that other countries will found that they cannot leave RMB and naturally won't hope RMB devaluation; then, they will naturally jointly maintain the value of RMB. For this reason, to propel the course of RMB internationalization, it is actually required to make RMB become a link of the world's standard currency; then, there will be an increase in international assets, the value of which is maintained with RMB; besides, due to the stable needs of bulk commodities, both the nation and enterprises will actively hold corresponding amount of RMB, laying a good foundation for further enhancing the credit in RMB, strengthening the international economic relation, and obtaining the pricing power of bulk commodities.

\section{Practically transforming the economic development mode to enhance the concentration ratio in industries}

China should transform existing economic development mode of high investment, high consumption and low benefits as soon as possible, and ceaselessly enhance the important position of China in the global industrial chain. With endeavor only in production cost, there is no more potential for China's production to exploit; the pricing power of bulk commodities cannot be automatically obtained just because we are the biggest purchaser or seller of partial commodities; however, enhancing the industrial concentration ratio plays a great role in obtaining the pricing power of bulk commodities. It is required to practically enhance the industrial concentration ratio, reduce the demands and demand-supply rigidity, promote the inter-enterprise cooperation in the same industry and continuously improve the utilization efficiency of resources. Practically integrate high-quality assets in the industry and implement the corresponding technical reserve and investment in new-type production capacities, so as to develop it towards the top of global value chain. Our country should actively cultivate and support some key enterprises having great influence and controlling force in the global trading market, and assist them in participation in market pricing of international bulk commodities. It is required to strengthen the macro control and guidance of relevant industries, and the issuance of industrial policies should be coordinated with the development of domestic and foreign markets, the connection between upstream and downstream industrial chains, etc., so as to maximize the national interests.

\section{Establishing a united foreign trading enterprise combination and coordination system}

China needs to actively encourage its enterprise to participate in international competition, set up a joint purchasing or sales alliance for import and export trade enterprises, and carry out external procurements or sales in united way so as to maximally enhance its ability of price negotiation 
overseas. It is required to practically establish an international trading combination system unanimously against the foreign side among enterprises, especially large-scale enterprise, concentrate to sign agreements against the foreign side, or consider introducing the open market auction mechanism and clarify success of the highest-price-offer so as to practically reduce the middle links. Of course, it is also required to industrial associations with good credibility and characteristic of de-administration so as to practically give play to the function of intermediary bridge and communication and coordination ability of industrial associations. An industrial association not only should provide enterprises with corresponding public services, safeguard Chinese foreign trading enterprises' interests and negotiate with foreigners on behalf of enterprises, but also should actively express and reflect enterprises' intentions and appeals to the government so as to influence the government's policies regarding the industry, import and export. In the long run, establishing a long-term and stable raw material industry chain should be the only way for Chinese enterprises to practically break through the international oligopoly. Under today's big trend of economic globalization, we can practically minimize the cost of raw materials and expand the import supply approach of China's important commodities by practically encouraging powerful domestic large-scale trading enterprises to go abroad, enlarging the intensity in developing and purchasing mineral resources worldwide by means of participation or investment holding etc. and forming a long-term stable raw material industry supply chain. Only in this way, can we get rid of unfavorable situation of being restricted by other countries and lacking discourse right for pricing of international bulk commodities. At present, China's government departments concerned have deeply recognized the vital significance of scare resources for the future development of Chinese economy, so they began to comprehensively reorganize the ambiguous bulk commodity import and export order. Chinese enterprises can enhance the pricing ability of bulk commodities in the pattern of global competition only by really eliminating backward and surplus capacity, better taking advantage of the country's status as a big trading nation on the global market with increasingly frequent fluctuations, effectively reducing the need of import and the rigidity of export supply, improving the structure of foreign trading products, more actively striving for the import of high-tech products, promoting the transformation and upgrading of processing trade industry with all strengths, guiding the local enterprise to go out, progressively transferring their own capacity overseas and realize the cooperation with mutual benefit and reciprocity on overseas resources.

\section{Implementing the technical innovation to break our predicament of lacking the pricing power}

China should transform our existing industrial development mode and industrial structure from a new strategic height, and practically enhance various enterprises' technical innovation abilities, so as to strengthen the important positions of our products and enterprises in the international industrial chain, enhance the international competitive abilities of domestic enterprises, and make them obtain a advantageous position in the global market and grasp the corresponding discourse power. Government departments should actively support enterprises' merging and reorganization, technical transformation, product structure upgrading, etc. through fiscal, taxation and other policies, guide enterprises in eliminating various outdated production capacities through merging and reorganization, enhance added value of products, and promote new development of our high-tech and environmental protection industries. Meanwhile, it is required to actively restrain enterprises' blind investment and repeated construction, so as to achieve effective combination of scientific achievements and production and truthfully turn technology into practical productivity.

\section{Conclusion}

To sum up, the pricing power of international bulk commodities is extremely important for our country to obtain the corresponding position in the international trading system. Only through concerted effort of relevant parties such as government, industry association, enterprises, etc., can we occupy the advantageous position in fighting for the pricing power of international bulk commodities, so as to gradually get rid of the existing difficulty in pricing power. Only by practically grasping the 
pricing power of international bulk commodities, can we have the initiative in the global commodity market, so as to maintain our national interests in a better way.

\section{References}

[1] Wu Chaoyang. Reasons for Lack of International Pricing Power for Imported Bulk Commodities and Corresponding Optimization, Modern Economic Research, 2011 (11).

[2] Xie Fei and Han Liyan. Speculation or Practical Demand: Analysis on Influencing Factors of Futures Price in International Commodities, Management World, 2012 (10).

[3] Huang He, Xie Wei and Ren Xiang. Pricing Mechanism of Global Bulk Commodities and Its Influence on China: The Perspective of Structural Power - - Taking the Pricing Mechanism of Iron Ore as an Example, Foreign Affairs Review (Journal of Foreign Affairs College), 2013 (2).

[4] Fan Linquan. Difficulty in and Path for Striving for International Pricing Power of Bulk Commodities, Modern Business Trade Industry, 2014 (9).

[5] Wang Shuyun. Thought on Enhancing Our Pricing Power of Bulk Resource-type Commodities, Commercial Times, 2014 (10). 